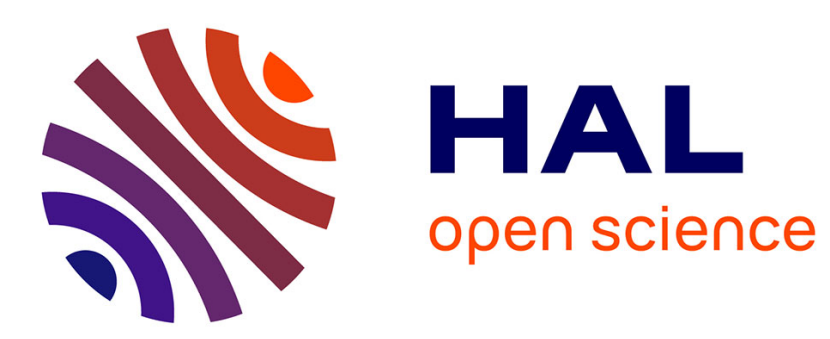

\title{
Models for Sample Selection Bias in Contingent Valuation: Application to Forest Biodiversity
}

\author{
Serge S. Garcia, Patrice Harou, Claire Montagné, Anne Stenger
}

\section{To cite this version:}

Serge S. Garcia, Patrice Harou, Claire Montagné, Anne Stenger. Models for Sample Selection Bias in Contingent Valuation: Application to Forest Biodiversity. Journal of Forest Economics, 2009, 15 (1-2), pp.59-78. 10.1016/j.jfe.2008.03.008 . hal-01072314

\section{HAL Id: hal-01072314 https://hal.science/hal-01072314}

Submitted on 31 May 2020

HAL is a multi-disciplinary open access archive for the deposit and dissemination of scientific research documents, whether they are published or not. The documents may come from teaching and research institutions in France or abroad, or from public or private research centers.
L'archive ouverte pluridisciplinaire HAL, est destinée au dépôt et à la diffusion de documents scientifiques de niveau recherche, publiés ou non, émanant des établissements d'enseignement et de recherche français ou étrangers, des laboratoires publics ou privés. 
Journal of Forest Economics. 2009, 15 (1-2) : 59-78

DOI 10.1016/j.jfe.2008.03.008

cop. Elsevier $\mathrm{GmbH}$

\title{
Models for Sample Selection Bias in Contingent Valuation: Application to Forest Biodiversity ${ }^{1}$
}

\author{
Serge Garcia, Patrice Harou, Claire Montagné, Anne Stenger
}

\begin{abstract}
In this article, we use two formats of contingent valuation (CV) questions to elicit willingness to pay (WTP) for maintaining biodiversity in forests: the dichotomous choice (DC) or referendum format and the open-ended (OE) question. A large population of French households were surveyed nationwide by phone. The sample of respondents was later divided into two subsamples: people who have recreational activities in forests and those who do not. This dichotomy potentially biases WTP as the decision to have recreational activities in forests is endogenous. We estimate a Probit model with sample selection to correct this bias in the DC question. With the OE question, a second source of selection bias related to nonrandom censoring is present: some respondents are unwilling to pay. We use an extension of Heckman's approach to the double selection problem. The empirical application shows that ignoring these sample selection problems leads to biased estimates of mean WTP for biodiversity in a national survey for France.
\end{abstract}

Keywords: Forest biodiversity, forest recreation, contingent valuation, sample selection bias, double selection

JEL Classification: C24, Q26 


\section{Introduction}

The background of this national survey of non-market goods and services in French forests has been given elsewhere (Peyron et al., 2002; Garcia et al., 2007). The main objectives of the survey were to: (1) value recreation in French forests using travel cost methods and underline the differences between the main regions of France, considering households' visits over two consecutive years; and (2) value biodiversity in French forests using a contingent valuation (CV) analysis. A questionnaire was designed with these two objectives in mind and was administered to households through a telephone interview. Given the complexities involved in biodiversity values, only the CV method was identified as adequate for such a national survey.

In this study, the scenario formulation of the CV survey is characterised by two questions on the willingness to pay (WTP) for biodiversity in forests: a dichotomous choice (DC), or referendum question, and an open-ended (OE) question. Two types of econometric models are usually used in this context: a Probit model for the DC question and a Tobit model for the OE question. The objective of this paper is to propose an econometric methodology that produces consistent parameter estimates and unbiased WTP giving special attention to the issue of sample selection bias.

Two main lines of research have addressed the issue of sample selection bias in contingent valuation studies. The first refers to the problem of non-response. Non-response is common and often important in CV surveys. A non-response bias occurs when some crucial characteristics of individuals are missing and when the two populations of respondents and non-respondents differ, resulting in different WTPs. Non-response can even lead to sample selection bias if each subsample differs in WTP because observable or non-observable characteristics are different for each subsample. The issue of sample selection bias (and of non-response bias) has been widely discussed (see for instance, Whitehead et al., 1993; Eklöf and Karlsson, 1997; Yoo and Yang, 2001).

The second problem in CV studies that can cause selectivity bias concerns protest votes. There exist two types of zero responses: a true zero value when respondents are truly averse or indifferent to the good for which a WTP is solicited, and a false zero value when the response provided is zero (although the true WTP is positive) due to an adverse reaction to the interview or to the payment vehicle. If protest values are considered as true zero values, then the mean WTP is biased downward; thus a minimal way to correct this bias is to remove the protest responses from the sample. However, this solution is not fully satisfactory since many observations might be discarded. Instead, one may use a sample selection model to take into account protest values and to correct any bias due to differences between the two populations of zero responses (see for instance Strazzera et al., 2003a; 2003b). 
An econometric treatment specific to sample selection problems is required in this study. However, the source of sample selection is different and especially important in a national survey as presented here. We have two types of respondents in the national survey: some have recreational activities in forests and others do not. It is likely that the WTP is different according to whether the respondent is a forest visitor or not. We suspect that disturbances in each equation (decision to visit and DC question) are correlated. Garcia et al. (2007) show efficiency gains in the estimation procedure using a simultaneous bivariate Probit equation model. If we want to compare the WTP of each group of respondents in the case where forest visitors and non-visitors are not drawn from the same population, then the sample selection problem should be accurately dealt with. Indeed, observed and non-observed characteristics of respondents could influence the choice of recreation in forests and WTP could differ according to the population under study. A corrective method for sample selection, analogous to that used by Heckman (1979), can be applied in the Probit analysis (van de Ven and van Praag, 1981).

In the case of the OE question, we consider a second source of potential selection bias that is related to censoring in the Tobit model. Some respondents are unwilling to pay whereas others give a strictly positive amount. The reason for this difference may be found in the individual characteristics of the respondents. Hence, the decision to pay or not may be explained by different factors even if they are still considered as dependent. The proper way to proceed would be to correct the bias that results from the estimation of the WTP equation from this nonrandom subsample (respondents who provide positive values). The correct approach is the standard Tobit with selectivity. The method used here consists in adapting Heckman's procedure to the case where two simultaneous and correlated sample selection problems (endogenous visit and positive WTP) occur. A model with double selection, as proposed by Ham (1982) and Tunali (1986), to estimate WTP is developed in our analysis to correct these two sources of selection bias.

The organisation of the article is as follows. In section 2, we briefly review the economic models for the DC and OE questions and explain the econometric methods used to correct the sample selection bias. Section 3 describes the survey and the data, while section 4 presents the results before concluding.

\section{Models}

The preferences of respondents for biodiversity conservation in forests are likely to be different according to many individual characteristics (e.g. income, age, interest in the forest). In addition, there are good reasons to think that the value given to biodiversity in forests is not the same depending on whether one is a visitor of forests or not $(V)$. If $V$ is used as an explanatory variable 
of differences in WTP but at the same time is determined endogenously (i.e. correlated with some observed or unobserved variables in the regression), the model is subject to selection bias. So if the value given to biodiversity is not independent from the probability of visiting forests by individuals with specific characteristics, then the validity of estimates in the WTP regression will be affected. We thus present a sample selection model for DC-CV analysis taking into account and correcting the bias due to the existence of two groups of individuals (forest visitors and non-visitors).

Concerning the OE question, zero and positive values ${ }^{2}$ are used to estimate WTP, but zero responses might be explained by some individual characteristics such as household income. Hence, these zero values may be non-random in nature. A Tobit model with selectivity such as that used by Köhlin (2001) taking into account the dependence between the decision to pay and the size of the payment could solve this problem. However, this selection bias due to non-random censoring adds to the selection bias due to forest visits explained above. Hence, we have to use a procedure for correcting the double selection bias.

\subsection{The DC question}

Let $I_{i}^{*}$ represent the difference in (indirect) utility with respect to the biodiversity level in forests $q$, which would take two values: $q_{1}$ for "preserved biodiversity" and $q_{0}$ for "altered biodiversity". The latent variable equation can be expressed as:

$$
I_{i}^{*}=X_{I i} \alpha+\varepsilon_{I i}
$$

where $X_{I i}$ is a vector of exogenous variables (including $t_{i}$, the amount proposed for preserving biodiversity), and $\alpha$ is the associated vector of parameters. If $I_{i}^{*}>0$ then the respondent $i$ is willing to pay $t_{i}$ and vice versa. The decision rule is thus:

$$
I_{i}= \begin{cases}1 & \text { if } I_{i}^{*}>0 \\ 0 & \text { otherwise }\end{cases}
$$

We now consider the case where the distribution of respondents according to whether they have recreational activities in forests or not is assumed to be non random. In this case, the sample selection rule is based on whether the respondent is a forest visitor $\left(V_{i}=1\right)$ or not $\left(V_{i}=0\right)$ conditionally to the unobserved measure $V_{i}^{*}$ of inclination of respondents to have recreational

\footnotetext{
${ }^{2}$ A follow-up question was asked when the answer was zero to the OE question with the objective to identify protest responses: "If the amount is equal to zero, is it because forest biodiversity is not really of interest to you or because you consider that you do not have to pay for that?" In our study, only true zero values are included in the WTP regression. Protest responses, i.e., when individuals are willing to pay something for a definite program but declare zero for reasons related to the process of valuation, are removed from the database, see Garcia et al. (2007).
} 
activities in forests:

$$
V_{i}= \begin{cases}1 & \text { if } V_{i}^{*}>0 \\ 0 & \text { otherwise }\end{cases}
$$

The latent variable equation is:

$$
V_{i}^{*}=X_{V i} \delta+\varepsilon_{V i}
$$

where $X_{V i}$ is a vector of exogenous variables, and $\delta$ is the associated vector of parameters.

The regression function associated to equation (1) for the sub-sample of observations $V_{i}^{*} \geq 0$ is:

$$
E\left(I_{i}^{*} \mid V_{i}^{*} \geq 0\right)=X_{I} \alpha+E\left(\varepsilon_{I i} \mid V_{i}^{*} \geq 0\right),
$$

Assuming that $\varepsilon_{I}$ and $\varepsilon_{V}$ are bivariate standard normally distributed with correlation coefficient $\rho_{I V}$, we have:

$$
E\left(\varepsilon_{I i} \mid V_{i}^{*} \geq 0\right)=\rho_{I V} \lambda_{i}
$$

where $\lambda_{i}=\frac{\phi\left(X_{V i} \delta\right)}{\Phi\left(X_{V i} \delta\right)}$ with $\phi$ and $\Phi$ respectively the standard normal probability density function (pdf) and the cumulative distribution function (cdf). Hence we can rewrite equation (1) as follows:

$$
I_{i}^{*}=X_{I} \alpha+\rho_{I V} \lambda_{i}+\widetilde{\varepsilon}_{I}
$$

where $E\left(\widetilde{\varepsilon}_{I} \mid V_{i}^{*} \geq 0\right)=0$ and $E\left(\widetilde{\varepsilon}_{I}^{2} \mid V_{i}^{*} \geq 0\right)=\tau_{i}^{2}=1+\rho_{I V}^{2} \lambda_{i}\left(X_{V i} \delta-\lambda_{i}\right)$.

Equation (7) is the new latent variable equation taking sample selection into account, whose estimates will be commented on in the Results section. As in Van de Ven and Van Praag (1981), we proceed in a three-step approach:

1. An estimation of the Probit model (3)-(4) is made giving consistent estimates $\hat{\delta}$ and thus also providing consistent estimates $\hat{\lambda}_{i}=\frac{\phi\left(X_{V i} \hat{\delta}\right)}{\Phi\left(X_{V i} \hat{\delta}\right)}$

2. Consistent OLS estimates of $\alpha$ and $\rho_{I V}$ are obtained from the linear probability model $I=$ $X_{I i} \alpha+\rho_{I V} \hat{\lambda}_{i}+\check{\varepsilon}_{I}$. Then $\tau_{i}^{2}$ can be replaced by $\hat{\tau}_{i}^{2}=1+\hat{\rho}_{I V}^{2} \lambda_{i}\left(X_{V i} \hat{\delta}-\hat{\lambda}_{i}\right)$ in the following step.

3. The Probit estimation technique is applied to equation (7) in which all explanatory variables $X_{I}, \hat{\lambda}_{i}$ and the error term are preliminarily divided by $\hat{\tau}_{i}$ in order to have a variance equal to one.

The Probit estimates $\hat{\alpha}$ and $\hat{\rho}_{I V}$ from the third step of the estimation procedure have to be considered as approximations since their error terms are not necessarily normally distributed. However, as noted by Van de Ven and Van Praag (1981), the ML estimates and the estimates of the Probit model with sample selection correction show a striking resemblance. 


\subsection{The OE question}

It is also possible to directly regress the maximum WTP on a set of exogenous variables when the respondent is asked to reveal the maximum amount he/she would pay. Hence, the respondent's WTP is estimated using a Tobit model for censored data. This model assumes that the WTP is a latent variable such that:

$$
W T P_{i}^{*}=X_{i} \gamma+\varepsilon_{i}
$$

where $X_{i}$ is a vector of exogenous variables, $\gamma$ is the associated vector of parameters, and $\varepsilon_{i}$ represent the errors, independently and normally distributed with mean zero and variance $\sigma^{2}$. However, what we observe is in fact the variable $W T P_{i}$ that is related to $W T P_{i}^{*}$ by the following rule: ${ }^{3}$

$$
W T P_{i}= \begin{cases}W T P_{i}^{*} & \text { if } W T P_{i}^{*}>0 \\ 0 & \text { otherwise }\end{cases}
$$

The probability associated to observations for which the variable $W T P_{i}$ is zero, is:

$$
P\left(W T P_{i}=0\right)=\Phi\left(-\frac{X_{i} \gamma}{\sigma}\right)
$$

For the positive values of $W T P_{i}$, we have:

$$
P\left(W T P_{i}>0\right) \times f\left(W T P_{i} \mid W T P_{i}>0\right)=f\left(\varepsilon_{i}\right)=\frac{1}{\sigma} \phi\left(\frac{W T P_{i}-X_{i} \gamma}{\sigma}\right)
$$

where $\phi($.$) is the standard normal pdf.$

Using a standard Tobit model implies that zero and positive values are assumed to be the expression of a unique choice model (Strazzera et al., 2003a). In other words, it assumes that the same factors affect both the decision to pay and the size of the payment, and it imposes the same structure on these two decisions (Köhlin 2001). If a non-random selection bias due to censoring is suspected, a more general approach is the Tobit model with selectivity. In such a model, we first estimate a Probit model to explain a positive WTP and then we report the inverse of Mill's ratio as an additional regressor in the positive WTP regression estimated by ordinary least squares (OLS). This leads to the well known two-step estimator of Heckman (1976).

\footnotetext{
${ }^{3}$ It may be argued that it is theoretically most correct to consider that the underlying dependent variable $W T P_{i}^{*}$ may be negative in some cases. However, in the valuation question to the respondents there is no trade-off offered between the good in question ("biodiversity") and other goods/services provided by forests. Hence, it seems more plausible to assume that the stated WTP of respondents who are indifferent about forest biodiversity is clustered at zero.
} 
Let the following system represent the Tobit model with selectivity:

$$
W T P_{i}= \begin{cases}X_{i} \gamma+\varepsilon_{i} & \text { if } Z_{i}^{*}>0 \\ 0 & \text { otherwise }\end{cases}
$$

where $Z_{i}^{*}=X_{Z i} \beta+\varepsilon_{Z i}$ is a latent variable, $X_{Z i}$ is a vector of exogenous variables, and $\beta$ is the associated vector of parameters. $\varepsilon_{Z i}$ and $\varepsilon_{i}$ are the random disturbances following a bivariate normal distribution with zero means and a correlation coefficient to be estimated. The sample rule is:

$$
Z_{i}= \begin{cases}1 & \text { if } Z_{i}^{*}>0 \\ 0 & \text { otherwise }\end{cases}
$$

However, we believe that the choice (WTP $=0$ or $W T P \geq 0)$ is endogenous, see equation (13), and also that the decision to visit a forest, equation (3), affects the maximum WTP declared by the respondent. Hence, we have to regress the maximum WTP with two selection rules defined by: (a) the non-random censoring of the OE question, and (b) the forest visit. The estimation procedure used here is an extension of Heckman's sample selection technique in the case where two correlated selection rules generate the sample. This procedure first gives estimates by bivariate Probit analysis: probability to pay a positive amount for forest biodiversity and probability to visit forests. The WTP equation is then regressed using the Probit coefficients to correct selectivity bias in the estimation. The econometric details of the estimation procedure are provided in the Appendix.

\section{Description of the survey and data}

Our data come from a national survey of a large sample of French households (Peyron et al., 2002). The questionnaire was administered by phone to 4,504 French households randomly chosen by départements within the French directory over the year 2002. These households were surveyed about their preferences and actual behaviours towards forest biodiversity protection and recreation in forests. We only deal with the part of this survey related to forest biodiversity preservation. The design of the CV scenario has already been fully described in Garcia et al. (2007).

A brief background relevant to the analysis that follows is presented here. From the survey, we know whether a person in the household visited forests in France for recreational activities in 2001. This allows us to build the dummy variable $V$ that is equal to one in the case of recreational visits to forests and zero otherwise. Several socio-economic variables that could affect the mean WTP are available such as the composition of households, the location of their residence (i.e., urban or rural area), or the type of housing. Moreover, we introduce several dummy variables for the opinion of 
respondents concerning forest exploitation ${ }^{4}$ to find out whether this can be a determinant of WTP. We also use in the econometric analysis geographical indicators for the location of household residence because they might capture unobserved heterogeneity on forest resources and the household behaviour. Descriptive statistics on all dependent variables used in our application are reported in Table 1.

\section{[ Table 1 here ]}

The scenario formulation of the $\mathrm{CV}$ method was characterised by two question formats for eliciting WTP: Dichotomous Choice (DC or referendum) and open-ended (OE). The DC approach appears to be incentive-compatible in many circumstances. Furthermore, many economists argued that most agents faced with an OE question would provide very broad WTP responses if they were acting strategically but not truthfully (Carson and Groves, 2007). However, this does not generally apply. Whether strategic behaviour leads to positive or negative bias is dependent on the respective incentives; there is no general result showing that strategic behaviour leads to overpledging.

Follow-up questions (such as OE questions) have been proposed as one way to improve the efficiency of DC questions. However, the well-known anchoring effect (also known as the starting point bias) occurs, implying a significant difference between the WTP distributions from initial and follow-up question responses (Herriges and Shogren, 1996). When an OE question about WTP is posed after a DC question, it would have to be expected that the OE result is biased towards the response of the DC question asked previously. Anchoring influences the OE folow-up question by pulling the response towards the anchor, yet have no effect on the DC question. However, the DC question alone is susceptible to anchoring effects (Green et al., 1998). Champ and Bishop (2006) conducted a review of 18 recent CV studies comparing different elicitation formats (OE, DC and payment card). The result of this review is that mean WTPs from the DC approach equalled or exceeded those based on the OE approach in almost all cases.

The DC format is such that the respondents have to report whether they are willing to pay a proposed amount $t$ or not. The amount $t$ was clearly given as $6,12,18, \ldots$ or $90 €$. We refer to the response as the dummy variable $I$ (equal to one if the proposed amount is accepted, zero otherwise).

The OE question asks for the maximum contribution the respondent would accept to pay. This maximum contribution is denoted WTP. For a 'yes' answer to the DC question, the maximum amount had to be at least equal to the proposed amount. For a 'no' response, it had to be at most

\footnotetext{
${ }^{4}$ The question related to the opinion on forest exploitation was initially asked in the part of the survey dedicated to the travel cost analysis.
} 
equal to the proposed amount. A follow-up question was asked only if the answer was zero to the second question to differentiate true zero values from protest responses.

For the purpose of our article, i.e., the study of interdependence between recreation in forests and WTP, we report in Table 2 the distribution of observations for the DC question according to $V$ and $I$.

[ Table 2 here ]

For the OE question, we report in Table 3 the distribution of observations according to $V$ and $Z$, where $Z=1$ in the case of positive WTP and $Z=0$ when the WTP is 0 .

[ Table 3 here ]

The final sample used for our empirical application contains 1,070 households. Most removed observations were non-responses and missing data, as well as 743 protest responses. ${ }^{5}$

\section{Results}

\subsection{The DC question}

Consider first the WTP estimation from the DC question. Estimates of the Probit models with and without sample selection correction are presented in Table 4. In the first column we report estimates of the selection equation (i.e. decision of visiting forests). In the second and third columns, we report estimates of the DC equation with selection correction, depending on whether respondents are forest visitors $(V=1)$ or not $(V=0)$. Results of the Probit model without selection correction but considering $V$ as an exogenous regressor are in the last column of Table 4. Details of the determinants of the selection equation are available in Garcia et al. (2007). We only comment here on the estimation results concerning the DC question with sample correction. Estimates of the DC equation without selection correction will be used to estimate the mean WTP. However, a rapid look at the estimates allows us to note numerous differences in parameter estimates according to whether the sample selection is considered or not.

\section{[ Table 4 here ]}

Our results show that the parameter estimate $\hat{\rho}_{I V}$ associated with $\lambda$ is significantly different

\footnotetext{
${ }^{5}$ See Garcia et al. (2007).
} 
from 0 in the case where $V=1$. This highlights the dependence between the decision to visit forests and the WTP of respondents and confirms the necessity to correct sample selection in order to obtain consistent parameter estimates (and consistent estimates of WTP) in the DC-CV analysis.

Concerning the regressors of the regression, several remarks can be made. As expected, the probability of accepting the proposed amount depends negatively on the value proposed to each respondent and is highly significant (at the 1\% level). We notice that the estimated parameter is equal to -0.0184 when the respondent is used to visiting forests whereas it is -0.0261 when he/she does not have recreational activities in forests. This result suggests that a forest visitor is more likely to be willing to pay a higher amount. The parameter associated with income is positive and significant (at the $1 \%$ level) but only for a forest visitor. The probability of accepting the proposed amount is significantly different with respect to the region of residence, and the results are different according to whether the respondent is a forest visitor or not. When they visit forests, WTP of respondents is significantly affected by their opinion on wood harvesting: if the household considers that timber harvesting contributes to forest maintenance, then its WTP is higher. Moreover, living in a city has a negative impact on WTP for biodiversity, but is significant only for a forest visitor.

\section{[ Table 5 here ]}

The estimated mean (and median) WTPs for forest visitors and non-visitors are reported in Table 5 for the Probit models with and without sample selection correction. For each subsample, mean WTP is computed for the average respondent (i.e., at the subsample mean of explanatory variables). Our results from the model with sample correction show that mean WTP is $65 €$ and highly significant when the respondent is a forest visitor whereas the mean WTP is much lower for non-visitors (with a value of $11.59 €$ significant at the $10 \%$ level). These results indicate that there is a large difference in WTP between the two subsamples of respondents. The results for the model without sample correction shows a similar mean WTP for forest visitors (a bit more than $63 €$ ). However, the estimate for non-visitors is higher with an amount of $30.35 €$, suggesting a large bias in estimates.

\subsection{The OE question}

We now turn to the presentation of results from the OE models. Three different WTP models are estimated:

- In Model 1, all observations are assumed to be randomly selected, so that we consider that there is no selection bias problem. Therefore, we have a standard Tobit model based on 
equation (8). Maximum likelihood estimation (MLE) is used from the total sample $(N=$ 1070). ${ }^{6}$

- Model 2 corrects the selection bias related to non-random censoring but $V$ (i.e. recreational visits in forests) is considered as exogenous. This is the well-known model Tobit with selectivity of Heckman (1976), see equations (12) and (13). The inverse Mill's ratio obtained from the first-step Probit estimation is a regressor in the WTP equation, which is consistently estimated by OLS for the sub-sample of observations $W T P_{i} \geq 0(N=860)$.

- Model 3 takes into account a double selection problem due to both non-random censoring and forest visits. This leads to the estimation of two equations according to two regimes: (R1) in which the respondent visits forest and has a positive WTP for biodiversity $\left(N_{1}=699\right)$, and (R2) in which the respondent does not visit any forests but has a positive WTP $\left(N_{2}=161\right)$. Consistent estimates of the modified inverse Mill's ratios obtained in the first-step estimation of the bivariate Probit model are reported in the WTP equations according to regimes R1 and R2. The OLS method provides consistent parameter estimates, see description in Appendix.

We start by presenting estimates of forest visits and censoring selection equations. These firststep estimates allow for the computation of the inverse Mill's ratios entering as regressors in Models with sample selection correction. The first column in Table 6 shows estimates used in Model 2, whereas the other columns show estimates of the bivariate Probit for Model 3. The null hypothesis that $\rho$ is zero is rejected at the $1 \%$ level, indicating the validity of jointly estimating the two selection equations for Model 3.

\section{[ Table 6 here ]}

Here, we do not detail the results of the probability of visiting forests that are available in Garcia et al. (2007). However, some comments on estimates of the two censoring equations $(Z)$ can be made. The estimates differ noticeably whether $V$ is considered as exogenous or not. In the univariate Probit equation where $V$ is a regressor, this variable has a large and significantly positive impact on the decision to pay a positive amount. In both equations, the parameter associated with income is significantly positive, but the estimate is lower when $V$ enters into the equation as a regressor (0.0491 vs. 0.0641). Regional differentiation also has a large impact in both cases: the probability not to pay is lower in Northern France. However, living in the Ile-de-France region has no significant impact in the univariate Probit whereas it is significantly positive in the bivariate Probit. If wood harvesting is negatively perceived by the respondent (i.e. spoiling the

\footnotetext{
${ }^{6}$ We use the procedure QLIM of the software SAS v9.1 to estimate the Tobit model.
} 
forest), then the probability to pay for biodiversity is higher (only significantly in the case where $V$ - is exogenous). Finally, the parameter associated with the size of household is positive but only significant (at the $10 \%$ level) in the bivariate Probit. Living in a city has no impact in either equation explaining the censoring.

\section{[ Table 7 here ]}

The results of the estimation of Models 1 to 3 are reported in Table 7 . Evidence of selection bias due to non-random censoring is shown in Model 2 by the significance (at the $5 \%$ level) of the coefficient $\lambda_{Z}$. Moreover, the coefficient of the selectivity correction variable related to forest visits $\left(\lambda_{V}\right.$ in Model 3$)$ is significantly different from 0 for both visitors and non-visitors, indicating that self-selection occurs when respondents provide a value for forest biodiversity. Hence, single equation models such as Model 1 that ignore the interdependence between the willingness to visit and recreate in forests and the WTP for biodiversity lead to biased estimates in this nationwide survey.

Several explanatory variables have a statistically significant impact on the size of WTP. Most of them affect the value of WTP positively. For instance, if the household lives in the Ile-de-France region $(z 1)$ then the WTP is significantly higher. If the household believes that wood harvesting maintains the forest (variable $E F$ ), then the WTP is also significantly higher. The size of household has a positive but non significant impact on the WTP.

There are differences according to the model and comparing the results allows us to measure the extent of bias when selection rules are not taken into account. The WTP in the Ile-de-France region is lower in Models 1 and 2 than in Model 3 (with a coefficient equal to 23.0649 and 28.2481 instead of values close to 50 in model 3). Moreover, living in Northern France has a positive and significant effect on WTP in Models 1 and 2 but not in Model 3. Living in a city has an opposite effect according to the model but always non-significant. Finally, the income effect is largely different according to the model. The coefficient associated with the income is significantly positive in R1 (with a value of 4.9219 and a standard error of 2.7868) but not different from zero in R2. Moreover, when respondents are not differentiated according to the selection rules, this effect is underestimated: the coefficient related to income is estimated to 1.2989 in Model 1 and 1.9121 in Model 2.

[ Table 8 here ] 
In Table 8, we report estimates of mean (and median) WTP from our three parametric models as well as a non-parametric estimation of mean and median WTP by the Kaplan-Meier estimator (see Bateman et al., 2002, pp.226-229). It is interesting to note that the same sample of respondents accepting to pay a positive amount $(N=860)$ presents the same mean value of WTP (respectively $38.64 €$ and $38.63 €$ ) whatever the estimation method used (parametric or non-parametric). This result seems to indicate that the distributional assumptions do not lead to biased estimates of WTP. We can also emphasize the interest of correcting selection bias related to forest visits. We compute two mean WTPs from Model 2 according to whether the respondent is a forest visitor or not. These estimates largely differ from those computed with Model 3. Indeed, if the sample selection problem is not taken into account, then mean WTP is overestimated for a forest visitor (50€ instead of $39.84 €$ ). On the other hand, when the respondent are not used to visiting forests, the mean WTP is underestimated (only $11.06 €$ and not significantly different from 0 , instead of $33.42 €)$.

\section{Concluding remarks}

In this paper, we have presented and implemented methods to consistently estimate WTP by correcting sample selection bias. In the context of this national survey, two selection rules are considered. The first one consists in separating households visiting and having recreational activities in forests from those who never visit any forests. We assume that the decision to visit forests is not randomly selected and that the two subsamples have different characteristics. These two types of respondents will thus present different mean WTPs. For the DC-CV analysis, a Probit model with sample selection allows us to correct this potential bias. When dealing with the OE question, a second selection rule is governed by a censored regression since a large number of respondents announce WTPs equal to zero. Therefore, for the analysis of the maximum WTP, we use a model with double selection to take into account both sample selection problems.

In our empirical application, we show that sample selection bias has major effects on parameter estimates and thus on estimates of mean WTP. In other words, not recognising that WTP for biodiversity is conditional on recreational activities in forests and that such activities are undertaken by only a part of population (interested in biodiversity) would move our estimate away from the true mean WTP of the population. The results obtained from the DC question make it possible to assign mean values of WTP for the total sample including true zero responses for forest visitors and non-visitors (respectively $65 €$ and $11.59 €$ ). The large difference in estimates of mean WTP for households who never visit any forests gives an indication of the bias scope: the model with sample selection produces a mean WTP equal to $11.59 €$ while it is equal to $30.35 €$ from a standard 
Probit model.

From the OE question and the sample selection procedure implemented, we obtain unbiased values for the portion of the population that gives a positive value to biodiversity. For our best specification (with double selection), mean WTPs are estimated at $39.84 €$ and $33.42 €$, respectively for forest visitors and non-visitors. Compared to the estimated mean WTPs provided by the DC-CV analysis, these estimates are not affected by potential bias related to zero responses. 


\section{References}

Bateman, I. J., R. T. Carson, B. Day, M. Hanemann, N. Hanley, T. Hett, M. Joneslee, G. Loomes, S. Mourato, E. Özdemiroglu, D. W. Pearce, R. Sugden, and J. Swanson (2002): Economic Valuation with Stated Preference Techniques: A Manual. Edward Elgar Publishing, Northampton, MA, USA.

Carson, R. T., and T. Groves (2007): "Incentive and informational properties of preference questions," Environmental and Resource Economics, 37(1), 181-210.

Champ, P. A., and R. C. Bishop (2006): "Is Willingness to Pay for a Public Good Sensitive to the Elicitation Format?," Land Economics, 82(2), 162-173.

EklÖF, J. A., And S. Karlsson (1997): "Testing and Correcting for Sample Selection Bias in Discrete Choice Contingent Valuation Studies," SSE/EFI Working Paper Series in Economics and Finance, No 171, Revised in 1999, Stockholm School of Economics, Sweden.

Fishe, R. P. H., R. P. Trost, and P. M. Lurie (1981): "Labor Force Earnings and College Choice of Young Women: An Examination of Selectivity Bias and Comparative Advantage," Economics of Education Review, 1(2), 169-191.

Garcia, S., P. Harou, C. Montagné, and A. Stenger (2007): "Valuing Forest Biodiversity from a National Survey in France: A Dichotomous Choice Contingent Valuation," Cahier du LEF no 2007-08, http://lef.nancy-engref.inra.fr/Docs/doc_LEF_n2007-08.pdf.

Green, D., K. E. Jacowitz, D. Kahneman, and D. McFadden (1998): "Referendum contingent valuation, anchoring, and willingness to pay for public goods," Resource and Energy Economics, 20(2), 85-116.

Ham, J. C. (1982): "Estimation of a Labour Supply Model with Censoring Due to Unemployment and Underemployment," Review of Economic Studies, 49(3), 335-354.

Heckman, J. J. (1976): "The Common Structure of Statistical Models of Truncation, Sample Selection, and Limited Dependant Variables and a Simple Estimator for Such models," The Annals of Economic and Social Measurement, 5, 475-492.

(1979): "Sample Selection Bias as a specification error," Econometrica, 47(1), 153-161.

Herriges, J. A., And J. F. Shogren (1996): "Starting Point Bias in Dichotomous Choice Valuation with Follow-Up Questioning," Journal of Environmental Economics and Management, $30(1), 112-131$. 
KÖHLIN, G. (2001): "Contingent valuation in project planning and evaluation: the case of social forestry in Orissa, India," Environment and Development Economics, 6(2), 237-258.

Lee, L.-F., G. S. Maddala, and R. P. Trost (1980): "Asymptotic Covariance Matrices of TwoStage Probit and Two-Stage Tobit Methods for Simultaneous Equations Models with Selectivity," Econometrica, 48(2), 491-503.

Peyron, J.-L., P. Harou, A. Niedzwiedz, and A. Stenger (2002): "National Survey on Demand for Recreation in French Forests," Report for EUROSTAT, Nancy, France. 44 pp.

Poirier, D. J. (1980): "Partial observability in bivariate probit models," Journal of Econometrics, 12(2), 209-217.

Strazzera, E., M. Genius, R. Scarpa, and G. Hutchinson (2003a): "The Effect of Protest Votes on the Estimates of WTP for Use Values of Recreational Sites," Environmental and Resource Economics, 25(4), 461-476.

Strazzera, E., R. Scarpa, P. Calia, G. Garrod, and K. Willis (2003b): "Modelling Zero Bids in Contingent Valuation Surveys," Applied Economics, 35(2), 133-138.

Tunali, I. (1986): "A General Structure for Models of Double-Selection and an Application to a Joint Migration/Earnings Process with Remigration," in Research in Labor Economics, Vol. 8, Part B, edited by Ronald G. Erhenberg, Greenwish: JAI Press Inc., 235-283.

Van de Ven, W. P. M. M., and B. M. S. Van PraAg (1981): "The Demand for Deductibles in Private Health Insurance : A Probit Model with Sample Selection," Journal of Econometrics, $17(2), 229-252$.

Whitehead, J. C., P. A. Groothuis, and G. C. Blomquist (1993): "Testing for Non-Response and Sample Selection Bias in Contingent valuation : Analysis of a Combination Phone/Mail Survey," Economics Letters, 41(2), 215-220.

Yoo, S.-H., And H.-J. YAng (2001): "Application of Sample Selection Model to Double-Bounded Dichotomous Choice Contingent Valuation Studies," Environmental and Resource Economics, 20(2), 147-163. 


\section{Appendix. Econometric approach: A model with double selection}

In this section, the subscript $i$ is dropped for notational convenience. The two selection equations are associated with two binary variables $V$ and $Z . V=1$ indicates that the respondent is used to visiting forests and $Z=1$ that the maximum WTP is strictly positive. In our Tobit framework, we do not estimate the case of zero $W T P$ values since $W T P$ is regressed by OLS only on its positive values (after taking into account the sample selection due to censoring). Therefore, $W T P$ is observed (or strictly positive) only in the two following regimes: $\left(R_{1}\right) V=1$ and $Z=1$ on the one hand, $\left(R_{2}\right) V=0$ and $Z=1$ on the other hand. The regimes $R_{3}$ and $R_{4}$ correspond to $W T P$ equal to 0 . We propose to illustrate these selection rules in Table 5.9.

[ Table 5.9 here ]

The two regimes $R_{1}$ and $R_{2}$ imply two distinct joint probabilities:

$$
\begin{aligned}
P_{R_{1}} & =\operatorname{Pr}(V=1, Z=1) \\
& =\operatorname{Pr}\left(V^{*}>0, Z^{*}>0\right) \\
& =\operatorname{Pr}\left(\varepsilon_{V} \leq A, \varepsilon_{Z} \leq B\right) \\
& =F(A, B, \rho)
\end{aligned}
$$

where $A=X_{V} \delta, B=X_{Z} \beta$ and $F(A, B, \rho)$ is the cdf of the standard bivariate normal distribution with correlation coefficient $\rho$.

$$
\begin{aligned}
P_{R_{2}} & =\operatorname{Pr}(V=0, Z=1) \\
& =\operatorname{Pr}(Z=1)-\operatorname{Pr}(V=1, Z=1) \\
& =\Phi(B)-F(A, B, \rho)
\end{aligned}
$$

where $\Phi($.$) denotes the standard normal cdf.$

These results lead us to write our model as the general model presented by Tunali (1986):

$$
\begin{array}{cc}
V^{*}=X_{V} \delta+\varepsilon_{V} & \text { first selection equation } \\
Z^{*}=X_{Z} \beta+\varepsilon_{Z} & \text { second selection equation } \\
W T P_{1}=X \gamma^{1}+\varepsilon_{1} & \text { regression equation regime } 1 \\
W T P_{2}=X \gamma^{2}+\varepsilon_{2} & \text { regression equation regime 2, }
\end{array}
$$


where $X_{V}, X_{Z}, X$ are vectors of exogenous variables and $\alpha, \beta, \gamma^{1}, \gamma^{2}$ their associated vectors of parameters. Moreover, we assume that the vector $\varepsilon=\left[\varepsilon_{V}, \varepsilon_{Z}, \varepsilon_{1}, \varepsilon_{2}\right]$ has a multivariate normal distribution:

$$
\left(\begin{array}{l}
\varepsilon_{V} \\
\varepsilon_{Z} \\
\varepsilon_{1} \\
\varepsilon_{2}
\end{array}\right) \sim N\left[\left(\begin{array}{l}
0 \\
0 \\
0 \\
0
\end{array}\right),\left(\begin{array}{cccc}
1 & \rho & \rho_{V 1} & \rho_{V 2} \\
\rho & 1 & \rho_{Z 1} & \rho_{Z 2} \\
\rho_{V 1} & \rho_{Z 1} & \sigma_{1}^{2} & \rho_{12} \\
\rho_{V 2} & \rho_{Z 2} & \rho_{12} & \sigma_{2}^{2}
\end{array}\right)\right]
$$

The derivation of the expected values of truncated errors has been described several times (see Fishe et al., 1981, or Tunali, 1986). Hence given the multivariate normal specification, the conditional expectation of error for the regime $R_{1}$ is:

$$
E\left(\varepsilon_{1} \mid V=1, Z=1\right)=\rho_{V 1} \lambda_{V 1}+\rho_{Z 1} \lambda_{Z 1},
$$

where $\lambda_{V 1}=\frac{\phi(A) \Phi(\tilde{A})}{P_{R_{1}}}$ and $\lambda_{Z 1}=\frac{\phi(B) \Phi(\tilde{B})}{P_{R_{1}}}$ are the inverse Mill's ratios modified for double selection, with $\tilde{A}=\frac{B-\rho A}{\sqrt{1-\rho^{2}}}$ and $\tilde{B}=\frac{A-\rho B}{\sqrt{1-\rho^{2}}}$. $\phi$ is the standard normal pdf and $P_{R_{1}}$ is defined in equation (14). For the regime $R_{2}$, the conditional expectation of error is:

$$
E\left(\varepsilon_{2} \mid V=0, Z=1\right)=\rho_{V 2} \lambda_{V 2}+\rho_{Z 2} \lambda_{Z 2},
$$

where $\lambda_{V 2}=-\frac{\phi(A) \Phi(\tilde{A})}{P_{R_{2}}}$ and $\lambda_{Z 2}=\frac{\phi(B) \Phi(-\tilde{B})}{P_{R_{2}}}$ are the inverse Mill's ratios modified for double selection, with $P_{R_{2}}$ defined in equation (15).

The Heckman two-stage estimator extended to the two selection rule problem was first described by Poirier (1980), Fishe et al. (1981) and Ham (1982), and then in a more general form by Tunali (1986). This consists in first estimating the bivariate Probit model defined by equations (16) and (17) with the MLE method. Consistent estimates of $\alpha, \beta$ and $\rho$ are obtained and used to compute consistent estimates $\widehat{\lambda}_{V 1}, \widehat{\lambda}_{Z 1}, \widehat{\lambda}_{V 2}$ and $\widehat{\lambda}_{Z 2}$ of respectively $\lambda_{V 1}, \lambda_{Z 1}, \lambda_{V 2}$ and $\lambda_{Z 2}$. The following equations are then estimated individually (i.e., $\rho_{12}$ is assumed to be 0 ) by OLS:

$$
\begin{aligned}
& W T P_{1}=X \gamma^{1}+\rho_{V 1} \widehat{\lambda}_{V 1}+\rho_{Z 1} \widehat{\lambda}_{Z 1}+\eta_{1} \\
& W T P_{2}=X \gamma^{2}+\rho_{V 2} \widehat{\lambda}_{V 2}+\rho_{Z 2} \widehat{\lambda}_{Z 2}+\eta_{2}
\end{aligned}
$$

where $\eta_{1}=\varepsilon_{1}-\rho_{V 1} \lambda_{V 1}-\rho_{Z 1} \lambda_{Z 1}$ and $\eta_{2}=\varepsilon_{2}-\rho_{V 2} \lambda_{V 2}-\rho_{Z 2} \lambda_{Z 2}$ are random errors with zero means. This implies that, even if all parameter estimates are consistent, their associated standard errors are not. We correct the covariance-variance matrix of parameter estimates as did by Ham (1982) and Tunali (1986) in their appendix. This is a simple generalisation of Heckman (1979) or Lee et al. (1980). 
Table 1: Definitions and descriptive statistics of the explanatory variables

\begin{tabular}{|c|c|c|c|c|c|}
\hline Variable & Description & Mean & Std. Dev. & Min. & Max. \\
\hline z1 & $\begin{array}{l}\text { Geographical indicator for the location } \\
\text { of household residence } \\
z 1=1 \text { for the Ile-de-France region. }\end{array}$ & 0.135 & 0.34 & 0 & 1 \\
\hline $\mathrm{z} 2$ & $\begin{array}{l}\text { Geographical indicator for the location } \\
\text { of household residence } \\
\text { z2 }=1 \text { for the North-Western part of France. }\end{array}$ & 0.203 & 0.40 & 0 & 1 \\
\hline $\mathrm{z} 3$ & $\begin{array}{l}\text { Geographical indicator for the location } \\
\text { of household residence } \\
\text { z3=1 for the North-Eastern part of France. }\end{array}$ & 0.223 & 0.42 & 0 & 1 \\
\hline $\mathrm{z} 4$ & $\begin{array}{l}\text { Geographical indicator for the location } \\
\text { of household residence } \\
z 4=1 \text { for the South-Eastern part of France. }\end{array}$ & 0.267 & 0.44 & 0 & 1 \\
\hline $\mathrm{z} 5$ & $\begin{array}{l}\text { Geographical indicator for the location } \\
\text { of household residence } \\
\text { z } 5=1 \text { for the South-Western part of France. }\end{array}$ & 0.172 & 0.38 & 0 & 1 \\
\hline GN & $\begin{array}{l}\text { Household's opinion about forest exploitation } \\
\text { GN=1 if "Timber harvesting spoils forest } \\
\text { landscape and obstructs forest access" }\end{array}$ & 0.140 & 0.35 & 0 & 1 \\
\hline $\mathrm{EF}$ & $\begin{array}{l}\text { Household's opinion about forest exploitation } \\
\mathrm{EF}=1 \text { if "Timber harvesting contributes } \\
\text { to forest maintenance" }\end{array}$ & 0.768 & 0.42 & 0 & 1 \\
\hline MA & $\begin{array}{l}\text { Household's opinion about forest exploitation } \\
\mathrm{MA}=1 \text { if "Timber harvesting provides a natural } \\
\text { and renewable material" }\end{array}$ & 0.322 & 0.47 & 0 & 1 \\
\hline City & $\begin{array}{l}\text { Location of the household's residence } \\
\text { City }=1 \text { if the household lives in an urban area }\end{array}$ & 0.529 & 0.50 & 0 & 1 \\
\hline Apart & $\begin{array}{l}\text { Type of housing for the household } \\
\text { Apart }=1 \text { if the household lives in an apartment }\end{array}$ & 0.334 & 0.47 & 0 & 1 \\
\hline Household & Total number of persons in the household & 2.85 & 1.41 & 1 & 10 \\
\hline Under 18 & $\begin{array}{l}\text { Number of young persons under } 18 \\
\text { in the household }\end{array}$ & 0.78 & 1.07 & 0 & 7 \\
\hline Income & $\begin{array}{l}\text { Indicator for the household's income } \\
\text { on the base of the average income of the } \\
\text { socio-professional group (ordered variable) }\end{array}$ & 5.57 & 2.84 & 1 & 11 \\
\hline
\end{tabular}

Notes: $\mathrm{N}=1070$. 
Table 2: Distribution of observations for the DC question

\begin{tabular}{cccc}
\hline & $I=0$ & $I=1$ & Total \\
\hline$V=0$ & 160 & 114 & 274 \\
$V=1$ & 292 & 504 & 796 \\
Total & 452 & 618 & 1070 \\
\hline
\end{tabular}

Notes: $V=1$ if the respondent is

a forest visitor; 0 otherwise.

$I=1$ if the respondent is willing

to pay $t ; 0$ otherwise.

Table 3: Distribution of observations for the OE question

\begin{tabular}{cccc}
\hline & $Z=0$ & $Z=1$ & Total \\
\hline$V=0$ & 113 & 161 & 274 \\
$V=1$ & 97 & 699 & 796 \\
Total & 210 & 860 & 1070
\end{tabular}

Notes: $V=1$ if the respondent is a forest visitor; 0 otherwise.

$Z=1$ if the respondent is willing to pay a positive amount;

0 otherwise (censoring). 
Table 4: Parameter estimates of the DC model

\begin{tabular}{|c|c|c|c|c|}
\hline \multirow[t]{2}{*}{$\begin{array}{l}\text { Probit } \\
\text { model }\end{array}$} & \multirow{2}{*}{$\begin{array}{c}\text { Selection } \\
\text { equation } \\
\qquad \\
V\end{array}$} & \multicolumn{2}{|c|}{$\begin{array}{l}\text { DC equation } \\
\text { with sample } \\
\text { correction }\end{array}$} & \multirow{2}{*}{$\begin{array}{c}\text { DC equation } \\
\text { without sample } \\
\text { correction } \\
I\end{array}$} \\
\hline & & $\begin{array}{c}I \\
(V=1)\end{array}$ & $\begin{array}{c}I \\
(V=0)\end{array}$ & \\
\hline Constant & $\begin{array}{c}-0.4973^{* * *} \\
(0.1936)\end{array}$ & $\begin{array}{c}0.0731 \\
(0.3725)\end{array}$ & $\begin{array}{c}0.6116 \\
(0.5658)\end{array}$ & $\begin{array}{c}0.2364 \\
(0.1924)\end{array}$ \\
\hline$t$ & & $\begin{array}{c}-0.0184^{* * *} \\
(0.0019)\end{array}$ & $\begin{array}{c}-0.0261^{* * *} \\
(0.0050)\end{array}$ & $\begin{array}{c}-0.0187^{* * *} \\
(0.0017)\end{array}$ \\
\hline Income & $\begin{array}{l}0.0659^{* * *} \\
(0.0160)\end{array}$ & $\begin{array}{l}0.0824^{* * *} \\
(0.0223)\end{array}$ & $\begin{array}{c}0.0750 \\
(0.0641)\end{array}$ & $\begin{array}{l}0.0528^{* * *} \\
(0.0150)\end{array}$ \\
\hline$z 1$ & $\begin{array}{l}0.5768^{* * *} \\
(0.1692)\end{array}$ & $\begin{array}{c}0.2340 \\
(0.1576)\end{array}$ & $\begin{array}{l}1.6671^{* * *} \\
(0.5909)\end{array}$ & $\begin{array}{c}0.2395^{*} \\
(0.1355)\end{array}$ \\
\hline$z 2$ & $\begin{array}{c}0.3084^{* *} \\
(0.1363)\end{array}$ & $\begin{array}{c}0.2702^{* *} \\
(0.1303)\end{array}$ & $\begin{array}{c}0.8847^{* *} \\
(0.3937)\end{array}$ & $\begin{array}{c}0.2848^{* *} \\
(0.1121)\end{array}$ \\
\hline$z 3$ & $\begin{array}{l}0.3749^{* * *} \\
(0.1349)\end{array}$ & $\begin{array}{c}0.1902 \\
(0.1241)\end{array}$ & $\begin{array}{c}0.2903 \\
(0.4186)\end{array}$ & $\begin{array}{c}0.0976 \\
(0.1071)\end{array}$ \\
\hline$z 4$ & $\begin{array}{l}0.4796^{* * *} \\
(0.1320)\end{array}$ & & $\begin{array}{c}0.7417 \\
(0.4562)\end{array}$ & \\
\hline$G N$ & $\begin{array}{c}-0.0830 \\
(0.1252)\end{array}$ & & & $\begin{array}{c}0.1038 \\
(0.1240)\end{array}$ \\
\hline$E F$ & $\begin{array}{l}0.2921^{* * *} \\
(0.1043)\end{array}$ & $\begin{array}{c}0.2609^{* *} \\
(0.1299)\end{array}$ & & $\begin{array}{c}0.0743 \\
(0.1030)\end{array}$ \\
\hline$M A$ & $\begin{array}{c}0.1676^{*} \\
(0.0952)\end{array}$ & & & $\begin{array}{r}-0.1100 \\
(0.0887)\end{array}$ \\
\hline Household & $\begin{array}{l}0.1426^{* * *} \\
(0.0523)\end{array}$ & & & $\begin{array}{c}-0.0450 \\
(0.0491)\end{array}$ \\
\hline Under 18 & $\begin{array}{c}-0.0676 \\
(0.0690)\end{array}$ & $\begin{array}{c}0.0490 \\
(0.0484)\end{array}$ & & $\begin{array}{c}0.0608 \\
(0.0633)\end{array}$ \\
\hline Apart & $\begin{array}{r}-0.1147 \\
(0.1119)\end{array}$ & & & $\begin{array}{c}0.0985 \\
(0.1073)\end{array}$ \\
\hline City & $\begin{array}{r}-0.1920^{*} \\
(0.1058)\end{array}$ & $\begin{array}{r}-0.1878^{*} \\
(0.1140)\end{array}$ & $\begin{array}{c}-0.2353 \\
(0.3044)\end{array}$ & $\begin{array}{c}-0.1212 \\
(0.1018)\end{array}$ \\
\hline$V$ & & & & $\begin{array}{l}0.6141^{* * *} \\
(0.0968)\end{array}$ \\
\hline$\lambda$ & & $\begin{array}{c}0.8525^{*} \\
(0.4735)\end{array}$ & $\begin{array}{c}-0.8280 \\
(0.8388)\end{array}$ & $\begin{array}{c}0.8525^{*} \\
(0.4735)\end{array}$ \\
\hline Log likelihood & -570 & -463 & -162 & -630 \\
\hline$N$ & 1070 & 796 & 274 & 1070 \\
\hline
\end{tabular}

Notes: Definitions of variables are in Table 1. Standard errors are in parenthesis. $* * *$ : significant at $1 \%, * *$ : significant at $5 \%, *$ : significant at $10 \%$. 
Table 5: Mean and median WTP for the DC question

\begin{tabular}{lcccc}
\hline \multirow{2}{*}{$\begin{array}{l}\text { Probit } \\
\text { model }\end{array}$} & \multicolumn{2}{c}{ with } & \multicolumn{2}{c}{ without } \\
& sample correction & \multicolumn{2}{c}{ sample correction } \\
& $V=1$ & $V=0$ & $V=1$ & $V=0$ \\
\hline Mean WTP $(€)$ & 65.00 & 11.59 & 63.23 & 30.35 \\
(Standard error) & $(3.21)$ & $(6.85)$ & $(4.46)$ & $(6.80)$ \\
$N$ & 796 & 274 & 1070 & 1070 \\
\hline
\end{tabular}

Notes: $V=1$ if the respondent is a forest visitor; 0 otherwise.

Table 6: Parameter estimates of selection equations for the OE question

\begin{tabular}{|c|c|c|c|}
\hline \multirow[t]{2}{*}{ Probit model } & \multirow{2}{*}{$\begin{array}{c}\text { Univariate } \\
\qquad Z\end{array}$} & \multicolumn{2}{|c|}{ Bivariate } \\
\hline & & $V$ & $Z$ \\
\hline Constant & $\begin{array}{c}-0.4471^{* *} \\
(0.1947)\end{array}$ & $\begin{array}{c}-0.4278^{* *} \\
(0.1777)\end{array}$ & $\begin{array}{c}-0.1348 \\
(0.1850)\end{array}$ \\
\hline Income & $\begin{array}{l}0.0491^{* * *} \\
(0.0178)\end{array}$ & $\begin{array}{l}0.0633^{* * *} \\
(0.0160)\end{array}$ & $\begin{array}{l}0.0641^{* * *} \\
(0.0170)\end{array}$ \\
\hline$z 1$ & $\begin{array}{c}0.2698 \\
(0.1797)\end{array}$ & $\begin{array}{c}0.5183^{* * *} \\
(0.1659)\end{array}$ & $\begin{array}{c}0.4086^{* *} \\
(0.1721)\end{array}$ \\
\hline$z 2$ & $\begin{array}{l}0.4146^{* * *} \\
(0.1502)\end{array}$ & $\begin{array}{c}0.2846^{* *} \\
(0.1362)\end{array}$ & $\begin{array}{l}0.4731^{* * *} \\
(0.1441)\end{array}$ \\
\hline$z 3$ & $\begin{array}{c}0.3065^{* *} \\
(0.1466)\end{array}$ & $\begin{array}{c}0.3594^{* * *} \\
(0.1356)\end{array}$ & $\begin{array}{c}0.3938^{* * *} \\
(0.1406)\end{array}$ \\
\hline$z 4$ & $\begin{array}{c}0.2349^{*} \\
(0.1389)\end{array}$ & $\begin{array}{l}0.4503^{* * *} \\
(0.1314)\end{array}$ & $\begin{array}{l}0.3530^{* * *} \\
(0.1331)\end{array}$ \\
\hline$G N$ & $\begin{array}{r}0.2427^{*} \\
(0.1468)\end{array}$ & $\begin{array}{c}-0.0841 \\
(0.1241)\end{array}$ & $\begin{array}{c}0.2013 \\
(0.1403)\end{array}$ \\
\hline$E F$ & $\begin{array}{c}0.0803 \\
(0.1152)\end{array}$ & $\begin{array}{l}0.2929^{* * *} \\
(0.1033)\end{array}$ & $\begin{array}{c}0.1619 \\
(0.1103)\end{array}$ \\
\hline$M A$ & $\begin{array}{c}0.1137 \\
(0.1040)\end{array}$ & $\begin{array}{c}0.1671^{*} \\
(0.0948)\end{array}$ & $\begin{array}{c}0.1520 \\
(0.0999)\end{array}$ \\
\hline Household & $\begin{array}{c}0.0239 \\
(0.0340)\end{array}$ & $\begin{array}{l}0.1091^{* * *} \\
(0.0313)\end{array}$ & $\begin{array}{c}0.0538^{*} \\
(0.0326)\end{array}$ \\
\hline City & $\begin{array}{c}0.0393 \\
(0.0980)\end{array}$ & $\begin{array}{c}-0.2479^{* * *} \\
(0.0895)\end{array}$ & $\begin{array}{c}-0.0368 \\
(0.0938)\end{array}$ \\
\hline$V$ & $\begin{array}{l}0.8678^{* * *} \\
(0.1002)\end{array}$ & & \\
\hline$\rho$ & & & \\
\hline Log likelihood & -468 & & \\
\hline
\end{tabular}

Notes: $\mathrm{N}=1070$. Standard errors are in parenthesis.

$* * *$ : significant at $1 \%, * *$ : significant at $5 \%, *$ : significant at $10 \%$.

$V=1$ if the respondent is a forest visitor; 0 otherwise.

$Z=1$ if positive values of $W T P ; 0$ otherwise (censoring).

In the univariate Probit model, visits are considered as exogenous.

Definitions of variables are in Table 1. 
Table 7: Determinants of WTP for the OE question

\begin{tabular}{|c|c|c|c|c|}
\hline \multirow[t]{2}{*}{ Model } & \multirow{2}{*}{$\begin{array}{c}\text { Model } 1 \\
\text { Tobit } \\
W T P\end{array}$} & \multirow{2}{*}{$\begin{array}{c}\text { Model } 2 \\
\text { Tobit with } \\
\text { selectivity } \\
\text { WTP }\end{array}$} & \multicolumn{2}{|c|}{$\begin{array}{l}\text { Model } 3 \\
\text { Regressions with } \\
\text { double selection }\end{array}$} \\
\hline & & & $W T P(\mathrm{R} 1)$ & $W T P(\mathrm{R} 2)$ \\
\hline Constant & $\begin{array}{c}-13.9121^{* *} \\
(5.5371)\end{array}$ & $\begin{array}{c}-46.1704 \\
(32.2999)\end{array}$ & $\begin{array}{r}-109.8079 \\
(85.9482)\end{array}$ & $\begin{array}{l}122.4550^{*} \\
(72.8589)\end{array}$ \\
\hline Income & $\begin{array}{l}1.2989^{* * *} \\
(0.4462)\end{array}$ & $\begin{array}{l}1.9121^{* *} \\
(0.8696)\end{array}$ & $\begin{array}{r}4.9219^{*} \\
(2.7868)\end{array}$ & $\begin{array}{c}-0.0466 \\
(2.1873)\end{array}$ \\
\hline$z 1$ & $\begin{array}{l}23.0649^{* * *} \\
(4.7727)\end{array}$ & $\begin{array}{l}28.2481^{* * *} \\
(7.8132)\end{array}$ & $\begin{array}{l}50.4763^{* *} \\
(22.8998)\end{array}$ & $\begin{array}{l}46.6186^{* * *} \\
(13.5259)\end{array}$ \\
\hline$z 2$ & $\begin{array}{c}9.5478^{* *} \\
(4.1390)\end{array}$ & $\begin{array}{l}13.9384^{*} \\
(8.3213)\end{array}$ & $\begin{array}{c}29.8609 \\
(20.8638)\end{array}$ & $\begin{array}{c}-13.9149 \\
(13.2812)\end{array}$ \\
\hline$z 3$ & $\begin{array}{c}6.0123 \\
(4.0749)\end{array}$ & $\begin{array}{c}9.3320 \\
(7.2872)\end{array}$ & $\begin{array}{c}27.9321 \\
(19.7941)\end{array}$ & \\
\hline$z 4$ & $\begin{array}{c}5.3193 \\
(3.9255)\end{array}$ & $\begin{array}{c}7.7774 \\
(6.5731)\end{array}$ & $\begin{array}{c}31.6642 \\
(19.6949)\end{array}$ & \\
\hline$G N$ & $\begin{array}{r}6.6892^{*} \\
(3.6659)\end{array}$ & $\begin{array}{c}9.8337 \\
(5.9898)\end{array}$ & & \\
\hline$E F$ & $\begin{array}{l}8.0849^{* * *} \\
(3.0779)\end{array}$ & $\begin{array}{l}10.7723^{* *} \\
(4.3700)\end{array}$ & $\begin{array}{l}23.1850^{* *} \\
(11.2091)\end{array}$ & $\begin{array}{c}24.8729^{* *} \\
(11.8322)\end{array}$ \\
\hline$M A$ & $\begin{array}{c}1.8392 \\
(2.6674)\end{array}$ & $\begin{array}{c}2.9266 \\
(3.9123)\end{array}$ & $\begin{array}{l}10.6623 \\
(8.5113)\end{array}$ & \\
\hline Household & $\begin{array}{c}0.0571 \\
(0.9084)\end{array}$ & $\begin{array}{c}0.3057 \\
(1.2880)\end{array}$ & $\begin{array}{c}5.4043 \\
(3.8749)\end{array}$ & $\begin{array}{c}3.5810 \\
(3.9279)\end{array}$ \\
\hline City & $\begin{array}{c}1.4234 \\
(2.583)\end{array}$ & $\begin{array}{c}1.6548 \\
(3.5903)\end{array}$ & $\begin{array}{r}-11.1839 \\
(8.6001)\end{array}$ & $\begin{array}{r}-11.4386 \\
(11.7217)\end{array}$ \\
\hline$V$ & $\begin{array}{l}21.6480^{* * *} \\
(3.0081)\end{array}$ & $\begin{array}{c}33.9290^{* *} \\
(13.9068)\end{array}$ & & \\
\hline$\lambda_{V}$ & & & $\begin{array}{c}115.4502^{*} \\
(62.3329)\end{array}$ & $\begin{array}{r}60.2962^{*} \\
(34.9360)\end{array}$ \\
\hline$\lambda_{Z}$ & & $\begin{array}{l}74.1017^{* *} \\
(32.8431)\end{array}$ & $\begin{array}{c}83.8797 \\
(97.3480)\end{array}$ & $\begin{array}{c}-32.4078 \\
(49.1409)\end{array}$ \\
\hline$N$ & 1070 & 860 & 699 & 161 \\
\hline $\begin{array}{l}\text { Estimation } \\
\text { method }\end{array}$ & MLE & $\begin{array}{l}\text { Corrected } \\
\text { OLS }\end{array}$ & $\begin{array}{l}\text { Corrected } \\
\text { OLS }\end{array}$ & $\begin{array}{l}\text { Corrected } \\
\text { OLS }\end{array}$ \\
\hline
\end{tabular}

Notes: Definitions of variables are in Table 1. Standard errors are in parenthesis.

$* * *$ : significant at $1 \%, * *$ : significant at $5 \%, *$ : significant at $10 \%$.

Regime (R1): $V=1$ (forest visitor) and $Z=1$ (positive WTP).

Regime (R2): $V=0$ (no forest visit) and $Z=1$ (positive WTP).

$\lambda_{V}$ and $\lambda_{Z}$ are the Mill's ratios modified for double selection. 
Table 8: Mean and median WTP estimates for the OE question

\begin{tabular}{lccccccc}
\hline $\begin{array}{l}\text { Estimation } \\
\text { method }\end{array}$ & Model 1 & Model 2 & $\begin{array}{c}\text { Model 2 } \\
(V=1)\end{array}$ & $\begin{array}{c}\text { Model 2 } \\
(V=0)\end{array}$ & $\begin{array}{c}\text { Model 3 } \\
(\mathrm{R} 1)\end{array}$ & $\begin{array}{c}\text { Non-parametric } \\
\text { (Kaplan-Meier) }\end{array}$ \\
\hline Mean WTP $(€)$ & 25.89 & 38.64 & 44.99 & 11.06 & 39.84 & 33.42 & 38.63 \\
(Standard error) & $(1.24)$ & $(1.70)$ & $(3.12)$ & $(11.42)$ & $(3.52)$ & $(5.38)$ & $(1.19)$ \\
Median WTP $(€)$ & 25.89 & 38.64 & 44.99 & 11.06 & 39.84 & 33.42 & 30.00 \\
$N$ & 1070 & 860 & 860 & 860 & 699 & 161 & 860 \\
\hline
\end{tabular}

Table 5.9: An illustrative example of combination of selection rules

\begin{tabular}{cccc}
\hline & $V$ & $Z$ & $W T P$ \\
\hline & & & \\
$R_{4}$ & 0 & 0 & 0 \\
& 0 & 0 & 0 \\
& 0 & 0 & 0 \\
\hline & 1 & 0 & 0 \\
$R_{3}$ & 1 & 0 & 0 \\
& 1 & 0 & 0 \\
& & & \\
\hline & 0 & 1 & $>0$ \\
& 0 & 1 & $>0$ \\
$R_{2}$ & 0 & 1 & $>0$ \\
& 0 & 1 & $>0$ \\
& 0 & 1 & $>0$ \\
& & & \\
\hline & 1 & 1 & $>0$ \\
& 1 & 1 & $>0$ \\
& 1 & 1 & $>0$ \\
$R_{1}$ & 1 & 1 & $>0$ \\
& 1 & 1 & $>0$ \\
& 1 & 1 & $>0$ \\
& 1 & 1 & $>0$ \\
& & & \\
\hline & & &
\end{tabular}

